\title{
First record of the invasive Australian redclaw crayfish Cherax quadricarinatus (von Martens, 1868) in the Crocodile River, Kruger National Park, South Africa
}

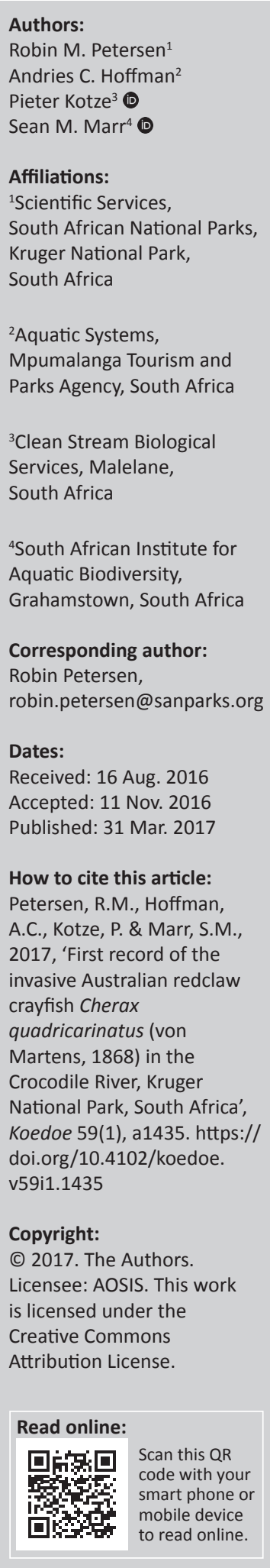

The redclaw crayfish Cherax quadricarinatus (von Martens, 1868), a robust freshwater crayfish native to Australia and Papua New Guinea, has now been recorded from the Kruger National Park (KNP). Previously absent from the Crocodile River, SAN Parks received a report in February 2016 of redclaw crayfish below the Van Graan Dam on the border of the KNP. Here, we provide evidence of the presence of redclaw crayfish in the Crocodile River. A better understanding of the redclaw crayfish distribution, habitat preferences, rate of spread and impacts on the local aquatic ecosystems in the Crocodile River is urgently required to develop mitigation strategies that minimise the spread of this invasive crayfish in the KNP and the Komati Catchment. The negative impacts of global crayfish introductions justify efforts to discourage further introductions and prevent their secondary spread.

Conservation implications: A better understanding of the redclaw crayfish distribution, habitat preferences, rate of spread and impacts on the local aquatic ecosystems in the Crocodile River is urgently required to develop mitigation strategies that minimise the spread of this invasive crayfish in the Kruger National Park and the Komati Catchment.

\section{Introduction}

Redclaw crayfish Cherax quadricarinatus (von Martens, 1868) is a robust freshwater crayfish native to Australia and Papua New Guinea (Ruscoe 2002). Tolerant of a broad range of environmental conditions (Masser \& Rouse 1997; Medley, Jones \& Avault 1994), the species has a simple reproductive cycle and fast growth rates (Masser \& Rouse 1997; Ruscoe 2002), making it of specific interest to the commercial aquaculture (Masser \& Rouse 1997; Medley et al. 1994; Ruscoe 2002; Saoud et al. 2013) and ornamental aquarium industries (Ahyong \& Yeo 2007; Belle et al. 2011). As a result, redclaw crayfish have been introduced into many regions including Latin America, the Caribbean islands, China, Taiwan, Swaziland, Zimbabwe, Zambia and the United States (Harlioğlu \& Harlioğlu 2006; Tyser \& Douthwaite 2014). Concern has been raised that the rapid expansion of redclaw crayfish in the Zambezi basin could threaten the Okavango Delta (Nunes et al. 2016).

A meta-analysis of global crayfish introductions found an overall negative ecological impact affecting all levels of freshwater food webs including reductions in the abundance and growth of macrophytes, aquatic invertebrates, amphibians and fish (Twardochleb, Olden \& Larson 2013). Negative impacts on macrophytes, invertebrates and fish were often coupled with positive effects on algal growth. The impact of a crayfish introduction was determined more by extrinsic characteristics of the recipient ecosystem than the species of crayfish introduced (Twardochleb et al. 2013). The potential impacts of C. quadricarinatus in South Africa include the destruction of aquatic macrophytes, disturbance of gravel beds used by substrate-spawning fish, predation on benthic macro-invertebrate communities and introduction of commensals, for example, parasites (De Moor 2002).

Although the redclaw crayfish has been evaluated as a potential aquaculture species in South Africa, the importation of this species has remained prohibited with all permit applications to import the species denied (De Moor 2002). However, redclaw crayfish were permitted to be imported into Swaziland in the 1990s for an aquaculture venture. The venture failed and a wild population of redclaw crayfish established in the Sand River Dam in Swaziland (De Moor 2002), and subsequently in the Sand River, a tributary of the Komati River, Komati Catchment by 1999 (De Moor 2002). The Sand River population have spread into the Komati River and its tributaries, including the Lomati River (De Villiers 2015) but was first recorded in South Africa in the Komati 
River in 2002 (De Villiers 2015). It was first reported in scientific literature from the outlet of Lake Nyamiti in Ndumo Game Reserve, Usuthu-Phongolo/Maputo River system in 2012 (Du Preez \& Smit 2013) and subsequently from two sites on the Komati River in 2015, one just upstream from the confluence with the Crocodile River (Tavakol et al. in press). The origin of the Lake Nyamiti population remains unresolved (Du Preez \& Smit 2013), as the Usuthu-Phongolo/ Maputo River system has no connection to the Komati Catchment. Although previously absent from the Crocodile River, SAN Parks received a report in February 2016 of redclaw crayfish below the Van Graan Dam on the southern border of the Kruger National Park (KNP). Here, we report a new locality record for redclaw crayfish in the Crocodile River.

\section{Methods}

Intensive sampling was conducted below Van Graan Dam on the Crocodile River on the southern boundary of the KNP in March 2016 because this was the location where the crayfish had been reported. The sluices of Van Graan Dam were temporarily closed (for roughly 40 minutes) to allow a thorough examination of the site below the dam wall. While the sluices were closed, specimens were collected using an electro-shocking device (SAMUS 4254) and hand netting, and some specimens were caught by hand. The cephalothorax length, weight and sex of crayfish captured were recorded. Specimens collected were preserved as vouchers for the South African National Parks Skukuza Biological Reference Collection. To establish the extent of the invasion, five additional sites, including above the Van Graan Dssam wall, along the Crocodile River were sampled over 3 days using five baited traps per site set overnight (Figure 1). The traps were constructed from PVC pipes (length $=700 \mathrm{~mm}$, diameter $=60 \mathrm{~mm}$ ) and chicken mesh wire to create a non-return entrance on each side. Commercial dog food pellets were used as bait. The traps were set in deep, slow-flowing habitats typically found above off-take weirs and bridges. Intensive sampling by wading at these sites was not possible because of the presence of crocodiles and hippopotamus.

\section{Results and discussion}

Crayfish (six males and three females) were only caught below Van Graan Dam (S -25.439773 ${ }^{\circ}$; E 31.635407º), while the sluices were closed, using electro-shocking. No crayfish were caught at the additional sites using the baited traps. The largest of which had $56 \mathrm{~mm}$ cephalothorax length and weighed $150 \mathrm{~g}$ (Figure 2); the smallest measured $39 \mathrm{~mm}$ and weighed $52 \mathrm{~g}$ (Table 1). The crayfish were captured in areas that are normally deep and fast flowing while the sluices are open. This was surprising because crayfish have in past surveys mostly been caught in deep, slow-moving water in the Komati River (A. Hoffman, pers. obs., n.d.). Our sampling in the Crocodile River intentionally targeted deep, slowflowing habitats, but this study indicates that future surveys should target other habitats on the Crocodile River.

This study confirms the presence of C. quadricarinatus in the Crocodile River. It is unclear at present whether redclaw crayfish colonised the site from downstream or were illegally introduced at the site. Possession of this species remains illegal in South Africa (De Moor 2002; Republic of South Africa 2014) but articles in farming magazines have extolled the economic potential of the species in aquaculture (Copeland 1999; Van Rooyen 2013) without demonstrating a clear understanding of the threat this species poses to aquatic biodiversity (De Moor 2002). From the current surveys, redclaw crayfish in the Crocodile River appears to be isolated to just below the Van Graan Dam, which may provide credence to suggestions that

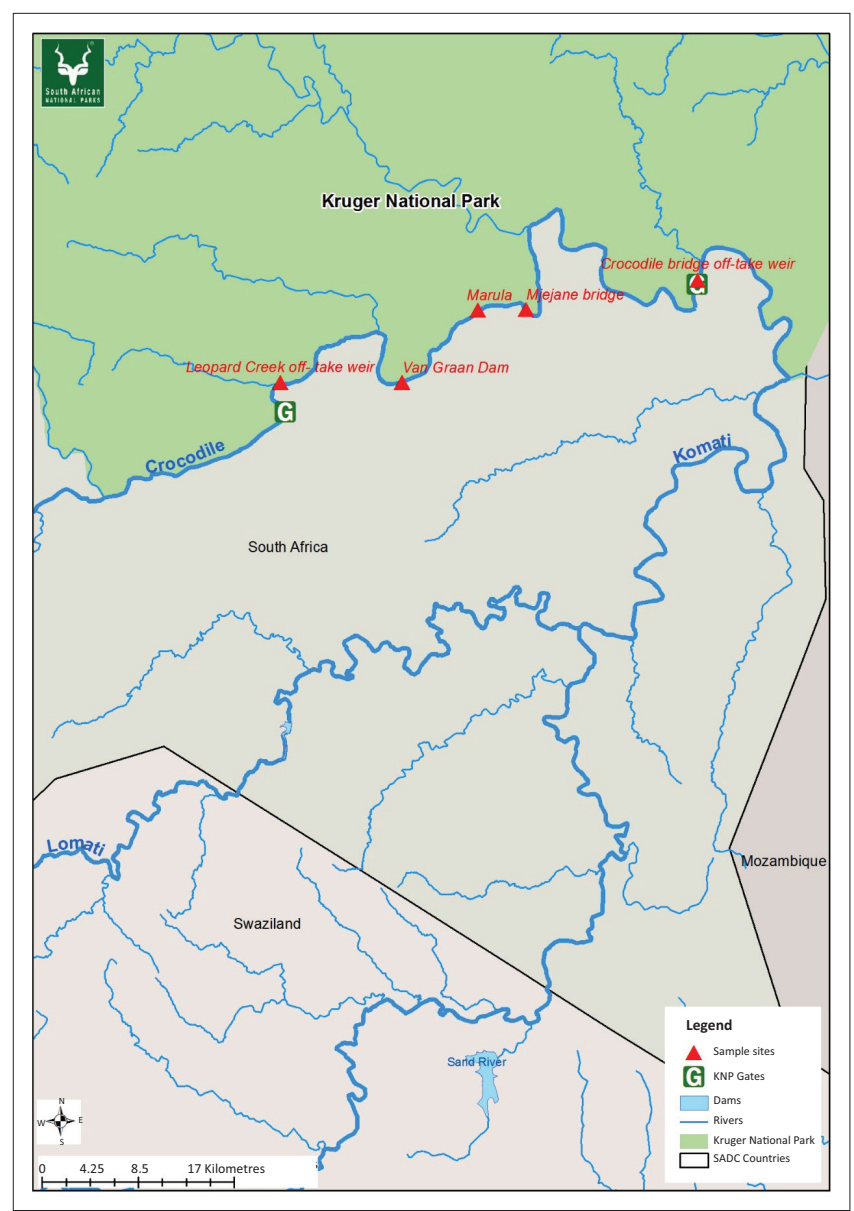

Source: South African National Parks

FIGURE 1: Map showing the location of the sites sampled in this study.

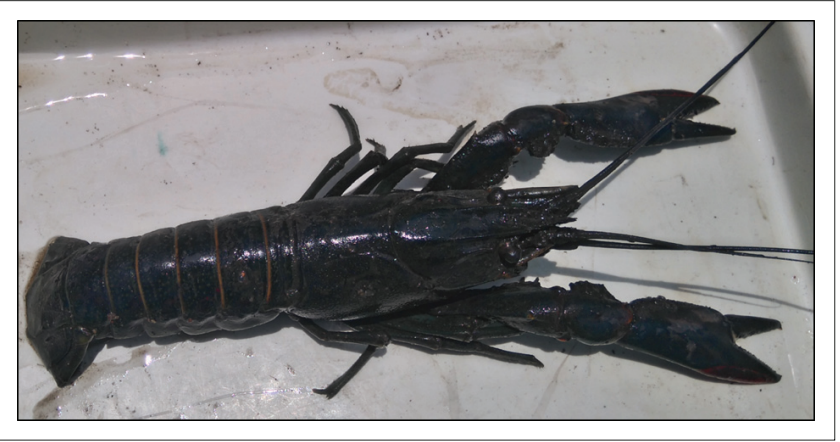

Source: Photo taken by Robin Petersen

Total body length $=270 \mathrm{~mm}$; cephalothorax length $=56 \mathrm{~mm}$.

FIGURE 2: Dorsal view of a male redclaw crayfish found in the Crocodile River, South Africa. 
TABLE 1: Record of measurements recorded for redclaw crayfish captured below Van Graan Dam, Crocodile River, on the border of the Kruger National Park.

\begin{tabular}{lccl}
\hline Specimen & $\begin{array}{c}\text { Cephalothorax } \\
\text { length }(\mathbf{m m})\end{array}$ & Weight $(\mathbf{g})$ & Sex \\
\hline 1 & 39 & 52 & Male \\
2 & 41 & 71 & Female \\
3 & 45 & 88 & Male \\
4 & 48 & 90 & Male \\
5 & 42 & 62 & Female \\
6 & 55 & 140 & Male \\
7 & 56 & 150 & Male \\
8 & 45 & 55 & Male \\
9 & 45 & 59 & Female \\
\hline
\end{tabular}

they have been illegally stocked at this locality. However, we cannot exclude colonisation from the Komati River and upstream via the Crocodile River because they were recently recorded from the Komati River just upstream of its confluence with the Crocodile River. The densities are currently low and no evidence of recruitment has been recorded to date, raising questions whether the population is self-sustaining at present. Both sexes and a range of size classes were, however, recorded at the site. Redclaw crayfish may have naturally colonised the site from the population in the Komati River, but in this scenario, one would expect to have evidence of the species at suitable sites between Van Graan Dam and the confluence between the Crocodile and Komati rivers. Further sampling is required to determine the extent of invasion of redclaw crayfish in the Crocodile River.

Freshwater biotic invasions are generally irreversible once the species have become established (Cucherousset \& Olden 2011). A better understanding of the redclaw crayfish distribution, habitat preferences, rate of spread and impacts on the local aquatic ecosystems in the Crocodile River is urgently required to develop mitigation strategies that minimise the spread of this invasive crayfish in the KNP and the Komati Catchment. The negative impacts of crayfish introductions justify efforts to discourage further introductions and prevent their secondary spread (De Moor 2002; Twardochleb et al. 2013).

\section{Acknowledgements}

The authors thank employees from SANParks, Mr Isaac Sedibe, our game guard and Ms Chenay Simms for producing the map. The authors also thank Mr Willie du Toit from the Crocodile Irrigation Board, Dr T.A. Zengeya from South African National Biodiversity Institute (SANBI) and Dr F. Roux from Mpumalanga Tourism and Parks
Agency (MTPA). The comments from the reviewers are also acknowledged.

\section{Competing interests}

The authors declare that they have no financial or personal relationships that may have inappropriately influenced them in writing this article.

\section{Authors' contributions}

R.M.P. was the project leader; A.C.H. and P.K. were responsible for experimental and project design and implementation. S.M.M. co-wrote the manuscript.

\section{References}

Ahyong, S.T. \& Yeo, D.C., 2007, 'Feral populations of the Australian red-claw crayfish (Cherax quadricarinatus von Martens) in water supply catchments of Singapore' Biological Invasions 9, 943-946. https://doi.org/10.1007/s10530-007-9094-0

Belle, C.C., Wong, J.Q., Yeo, D.C., Tan, S., Tan, H.H., Clews, E. et al., 2011, 'Ornamental trade as a pathway for Australian redclaw crayfish introduction and establishment', Aquatic Biology 12, 69-79. https://doi.org/10.3354/ab00324

Copeland, J., 1999, 'Rich pickings from crayfish', Farmer's Weekly, 8 October, 1999, p. 89-91.

Cucherousset, J. \& Olden, J.D., 2011, 'Ecological impacts of non-native freshwater fishes', Fisheries 36, 215-230. https://doi.org/10.1080/03632415.2011.574578

De Moor, I., 2002, 'Potential impacts of alien freshwater crayfish in South Africa', African Journal of Aquatic Science 27, 125-139. http://dx.doi.org/10.2989/16085 914.2002.9626584

De Villiers, M., 2015, 'Freshwater crayfish found in the Komati River', Lowvelder, 08 July, 2015, viewed n.d., from http://lowvelder.co.za/279853/crayfish-web/

Du Preez, L. \& Smit, N., 2013, 'Double blow: Alien crayfish infected with invasive temnocephalan in South African waters', South African Journal of Science 109 1-4. https://doi.org/10.1590/sajs.2013/20130109

Harlioğlu, M.M. \& Harlioğlu, A.G., 2006, 'Threat of non-native crayfish introductions into Turkey: Global lessons', Reviews in Fish Biology and Fisheries 16, 171-181. https://doi.org/10.1007/s11160-006-9010-1

Masser, M.P. \& Rouse, D., 1997, Australian red claw crayfish, Southern Regional Aquaculture Center, Stoneville, SRAC Publication No. 244.

Medley, P.B., Jones, C.M. \& Avault, J.W., Jr., 1994, 'A global perspective of the culture of Australian redclaw crayfish, Cherax quadricarinatus: Production, economics and marketing', World Aquaculture 25, 4 .

Nunes, A.L., Douthwaite, R.J., Tyser, B., Measey, G.J. \& Weyl, O.L.F., 2016, 'Invasive crayfish threaten Okavango Delta', Frontiers in Ecology and the Environment 14, 237-238. https://doi.org/10.1002/fee.1287

Republic of South Africa, 2014, Government Notice No. 37885. Vol. 590, Regulation Gazette No. 10244, Government Publishing Works.

Ruscoe, I., 2002, Fishnote 32: Redclaw crayfish aquaculture, Darwin Fisheries, Northern Territory Government, Australia.

Saoud, I.P., Ghanawi, J., Thompson, K.R. \& Webster, C.D., 2013, 'A review of the culture and diseases of redclaw crayfish Cherax quadricarinatus (von Martens, 1868)', Journal of the World Aquaculture Society 44, 1-29. https://doi.org/10.1111/jwas.12011

Tavakol, S., Luus-Powell, W.J., Smit, W.J., Baker, C., Hoffman, A. \& Halajian, A., in press, 'First introduction of two species of Australian Temnocephalans into Africa with an alien host: Double trouble', Journal of Parasitology. https://doi.org/10.1645/15-936

Twardochleb, L.A., Olden, J.D. \& Larson, E.R., 2013, 'A global meta-analysis of the ecological impacts of nonnative crayfish', Freshwater Science 32, 1367-1382. https://doi.org/10.1899/12-203.1

Tyser, A. \& Douthwaite, R., 2014, 'Predation on invasive redclaw crayfish Cherax quadricarinatus by native fishes in the Kafue River, Zambia', African Journal of Aquatic Science 39, 473-477. https://doi.org/10.2989/16085914.2014.980774

Van Rooyen, L., 2013, 'Feral freshwater crayfish: Ideal food', Farmer's Weekly, 16 September, 2013, viewed n.d., from http://www.farmersweekly.co.za/agritechnology/farming-for-tomorrow/feral-freshwater-crayfish-ideal-food/ 